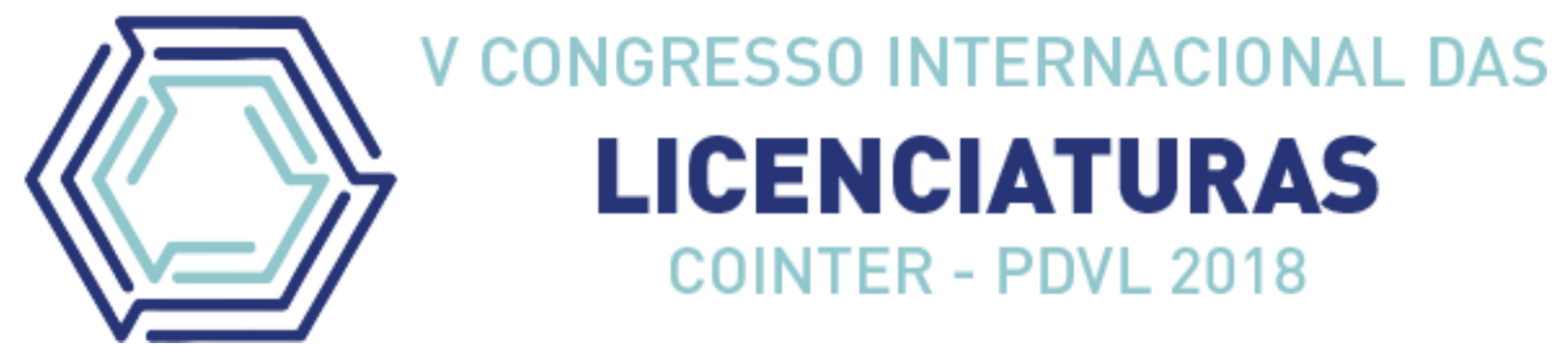

\title{
A IMPORTÂNCIA DO I ENCONTRO PIBID 2018 PARA OS NOVOS BOLSISTAS DE LICENCIATURA LETRAS ESPANHOL
}

\section{THE IMPORTANCE OF THE 1ST MEETING PIBID 2018 FOR NEW SCHOLARSHIPS OF LICENSEE SPANISH LETTERS}

\author{
Apresentação: Relato de Experiência
}

Isabel Angelo do Nascimento ${ }^{1}$; Nathasha Rayara Macedo Xavier da Silva ${ }^{2}$; Christiany Maria Rodrigues Bezerra ${ }^{3}$; Maria Trinidad Pacherrez Velasco ${ }^{4}$

DOI: https://doi.org/10.31692/2358-9728.VCOINTERPDVL.2018.00255

\section{Introdução}

A proposta deste trabalho é expor a importância do I encontro do Programa Institucional de Bolsa de Iniciação à Docência (PIBID) para os licenciandos do curso de Licenciatura em letras Espanhol do Instituto Federal do Rio Grande do Norte - IFRN que por primeira vez participam no programa. Nesta ocasião, os estudantes tiveram a oportunidade de conhecer a organização estrutural do Programa PIBID através da cuidadosa explanação das atividades o que se traduz para os estudantes numa satisfatória localização no complexo organograma do programa.

\section{Relato de Experiência}

O Programa Institucional de Bolsa de Iniciação à Docência (PIBID) divulgado para as Instituições de Ensino Superior (IES) na Portaria da Coordenação de Aperfeiçoamento de Pessoal de Nível Superior- CAPES com chamada pública através do edital nº 7-2018-PIBID, proposto aos estudantes do curso de licenciatura em Letras Espanhol do Instituto Federal do Rio Grande do Norte- IFRN, é um programa institucional do governo federal, exclusivo para estudantes de licenciatura, que tem como objetivo incentivar a formação docente em nível superior para rede básica do ensino público, valorizando-o e contribuindo para sua evolução. É uma oportunidade única para vivenciar a realidade da atual situação do ensino público,

\footnotetext{
${ }^{1}$ Estudante de Licenciatura Letras Espanhol, IFRN, isabelangelo04@gmail.com

2 Estudante de Licenciatura Letras Espanhol, IFRN, nathasharayara@gmail.com

${ }^{3}$ Estudante de Licenciatura Letras Espanhol, IFRN, christiany.rodrigues@hotmail.com

${ }^{4}$ Professora doutora em Língua Espanhola, IFRN, maria.velasco@ifrn.edu.br
} 
colocando em prática o que é visto em teoria.

Nós estudantes do curso de Licenciatura Letras Espanhol tivemos a oportunidade de ingressar no programa através do edital nº49/2018-DG/CNAT/IFRN, o qual classificou os estudantes a partir de critérios acadêmicos como o Índice de Rendimento Acadêmico e a origem escolar do estudante, sendo critério importante, ter cursado o ensino básico em escola pública.

Iniciamos as atividades PIBID no mês de agosto de 2018 com bastante expectativa com um encontro que contou com a participação do Coordenador de área, dos docentes supervisores (3) e licenciandos do curso de letras Espanhol (24), no qual, de início, foram explicitadas as diretrizes que se encontram no edital $n^{\circ} 7-2018$ - PIBID, esclarecendo as atribuições para cada participante.

Nessa ocasião ficamos cientes de que a escola-campo em que ficaríamos atuando seria a Escola Estadual Zila Mamede, o que nos causou muita curiosidade e ansiedade por conhecer mais a respeito da mesma. Conhecemos os supervisores das outras escolas participantes, tais como: Escola Estadual Atheneu Norte-Riograndense e Escola Estadual Berilo Wanderley.

O objetivo do I encontro PIBID 2018, configurado como evento de extensão no CNAT-IFRN, aconteceu no dia 10 de agosto de 2018, às $14 \mathrm{~h}$ da tarde e teve na sua programação, além da apresentação do que hoje implica em PIBID, ampla explicação e diálogo a respeito dos documentos que o regem atualmente, o que impactou de modo positivo, pois encontramos que é de extrema importância esse conhecimento para que saibamos a relevância social desse programa e compara-lo com os antigos projetos e sua evolução ao momento atual em que ele se encontra.

Num segundo momento tivemos contato com os supervisores de todas as escolas, foi um momento de integração entre todos os envolvidos no programa o que causou em nós grande satisfação por saber que teríamos apoio de todos e principalmente acompanhamento do supervisor responsável pela escola onde debutaríamos na prática docente na forma de oficinas de língua espanhola no contexto do PIBID.

Outro ponto importante desse momento foi o fato de vermos e sentirmos a concatenação das partes e a seriedade em que o programa PIBID Letras Espanhol Presencial se estabelece no CNAT/IFRN, garantido pela participação ativa dos supervisores das escolas que são os docentes responsáveis pela disciplina de espanhol na escola do estado, todos eles e nós estudantes bolsistas sob a coordenação de área, docente doutor e de área específica de 
formação do IFRN.

No momento de aproximação entre os membros, supervisores e coordenação e na troca de experiências e informações, podemos perceber a importância do PIBID, pois nos estava permitindo acesso a uma perspectiva ampla e real a respeito do que vamos enfrentar futuramente na prática profissional da docência.

Da apresentação do edital no7-2018- PIBID, podemos constatar o compromisso que o programa possui com nós licenciandos ao sermos alvo e partícipes do "incentivar a formação de docentes em nível superior para a educação básica; contribuir para a valorização do magistério; elevar a qualidade da formação inicial de professores nos cursos de licenciatura, promovendo a integração entre educação superior e educação básica; inserir os licenciandos no cotidiano de escolas da rede pública de educação, proporcionando-lhes oportunidades de criação e participação em experiências metodológicas, tecnológicas e práticas docentes de caráter inovador e interdisciplinar que busquem a superação de problemas identificados no processo de ensino-aprendizagem; incentivar escolas públicas de educação básica, mobilizando seus professores como co-formadores dos futuros docentes e tornando-as protagonistas nos processos de formação inicial para o magistério".

A relevância desse encontro está na luz com que conseguimos melhor compreender a tarefa e os desafios que vamos enfrentar, sentindo-nos encorajados, criando em nós uma vontade maior de querer viver a docência desta vez do lado contrário, como "docentes", pois a maioria de nós já a temos vivenciado a rede básica e pública como estudantes. Na atualidade e como estudantes de ensino superior do IFRN nos debruçamos em buscar, para nós e para os das escolas estaduais, a valorização da educação pública respaldados nas ações do PIBID, programa do MEC e da IES IFRN, entidades que promovem e fazem realidade esta oportunidade.

Imagem 1: Evento PIBID 2018. Fonte: Própria

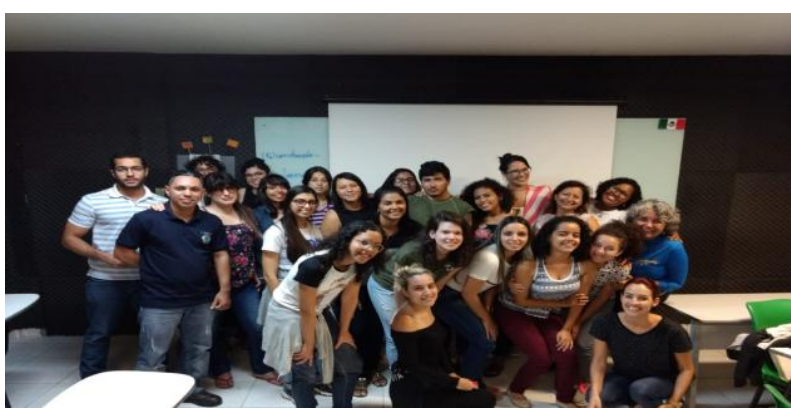

Imagem 2: Evento PIBID 2018. Fonte: NUPELE

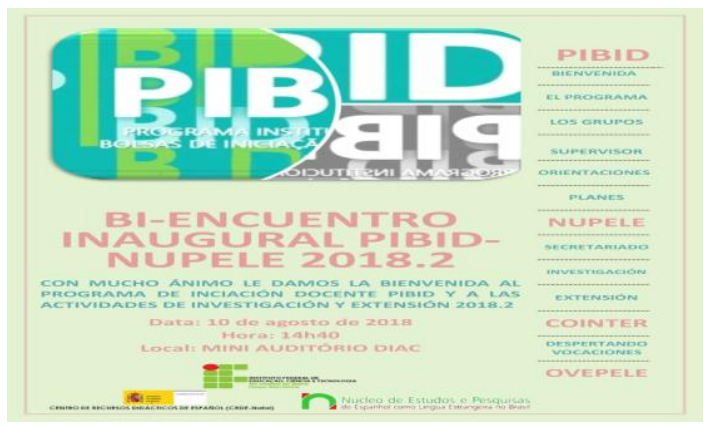




\section{Considerações}

A partir da vivência deste I encontro PIBID 2018, obtivemos as orientações iniciais, gerando em nosso entendimento importante expectativa e ânimo para fazer tudo que for preciso realizando atividades acadêmicas no contexto PIBID que contribuam à melhora da realidade do ensino médio público, gerando beneficio para os estudantes de licenciatura na hora de associar a prática e a teoria vista em sala de aula. Acreditamos de especial importância o fato de estarmos tendo eventos internos como esse que se configuram como atividade de extensão institucional, para sempre ter um acompanhamento no nosso papel de bolsistas estudantes durante o período que o programa PIBID estiver permitindo trocar experiências de ensino, visando enxergar formas distintas de aprender, contribuir e auxiliar tanto na nossa vida acadêmica como na dos alunos de ensino médio que participarão desse programa em suas escolas, tudo isso contribuindo para um ensino público de qualidade, assim como de uma formação docente consciente e clara na observação da realidade escolar.

\section{Referências}

BRASIL. EDITAL CAPES no 7-2018 -PIBID. Chamado público para apresentação de propostas por parte das instituições de ensino superior (IES). Disponível em <https://www.capes.gov.br/images/stories/download/editais/01032018-Edital-7-2018PIBID.pdf >Acesso em 02/09/2018.

INSTITUTO FEDERAL DE EDUCAÇÃO, CIÊNCIA E TECNOLOGIA DO RIO GRANDE DO NORTE. Projeto Pedagógico do Curso de Licenciatura Letras Espanhol Campus Natal Central. Deliberação $\mathrm{n}^{\circ}$ 45/2014-CONSEPEX. Disponível em: <http://portal.ifrn.edu.br/campus/natalcentral/cursos/cursos-de-graduacao/espanhol.html> Acesso em: 24 out. 2018. 